\title{
Nephrotic Syndrome Outcome in Children: An Epidemiological Study
}

\author{
Parsa Yousefichaijan ${ }^{1}$, Masoud Rezagholizamenjany $\left(\mathbb{D D}^{2,}{ }^{,}\right.$, Fatemeh Rafiei ${ }^{3}$, Ali Arjmand ${ }^{4}$ and Sima \\ Tayebi $^{2}$ \\ ${ }^{1}$ Department of Pediatric Nephrology, Amir Kabir Hospital, Arak University of Medical Sciences, Arak, Iran \\ ${ }^{2}$ School of Medicine, Arak University of Medical Sciences, Arak, Iran \\ ${ }^{3}$ Departmanof Biostatistics, Endocrinology and Metabolism Research Center, Arak University of Medical Sciences, Arak, Iran \\ ${ }^{4}$ Department of Pediatric, Amir Kabir Hospital, Arak University of Medical Sciences, Arak, Iran \\ "Corresponding author: Masoud Rezagholizamenjany, Arak University of Medical Sciences, Arak, Iran. Tel/Fax: +86-34573785, E-mail: masoudrezagholi074@gmail.com
}

Received 2017 October 06; Revised 2018 February 08; Accepted 2018 February 14.

\begin{abstract}
Background: Nephrotic syndrome (NS) as a glomerular basal membrane disease has different outcomes. The current study aimed at evaluating epidemiologic status in NS and its correlation with the outcome in children.

Methods: The current hospital based study evaluated the patients of pediatric clinic at Amir-Kabir hospital. Demographic information was obtained by interviewing both the physicians and patients. Also, to determine the sesitivityto steroid drugs, children were given prednisolone $(2 \mathrm{mg} / \mathrm{kg} /$ day with maximum dose of $60 \mathrm{mg} /$ day) for four weeks and syndromes were determined based on children responses to the drug. Patients were divided into four groups of 25 . At the end, data were transfered to SPSS program and the correlations between epidemiological information and different types of NS were investigated

Results: Results of the current study showed that steroid responded children with frequent relapse as well as steroid dependent children had better epidemiological and socioeconomic status compared with the steroid resistance ones $(\mathrm{P}<0.05)$.

Conclusions: Prognosis of NS or medication responses was related to epidemiological status of children.
\end{abstract}

Keywords: Nephrotic Syndrome, Epidemiology, Children

\section{Background}

Nephrotic syndrome (NS) as glioblastoma multiforme (GBM), in medicine and urology has a set of clinical manifestations due to increased glomerular membrane permeability, which occur due to high protein excretion (1, 2 ). Since non-nephrotic kidney has a low urinary protein excretion ( $\mathrm{Up} / \mathrm{Cr}<0.2$ or $<4 \mathrm{mg} / \mathrm{m}^{2} /$ hour), excretion increases and reaches more than 2.0 U PR/Cr or 40 $\mathrm{mg} / \mathrm{m}^{2}$ /hour, which leads to some clinical manifestations including edema hypoproteinemia, and lipoproteins $(3,4)$. In children and young adults, this is almost invariably the continuum clinical counterpart of glomerular diseases in minimal change disease (MCD) and mesangial proliferative GN (MesGN) (5).

This syndrome, based on outcome, is divided into transient, persistent, asymptomatic, symptomatic, orthostatic, and fixed in types $(6,7)$. Syndrome treatment, independent of the underlying renal pathology, is by continuously taking prednisone for four weeks, as the basic approach of treatment, which in approximately 90\% of children with MCD and $20 \%-60 \%$ of those with focal segmental glomerulosclerosis (FSGS) achieves remission $(8,9)$. How- ever, after steroid tapering or withdrawal, $60 \%-70 \%$ of patients relapsed and most of them required repeated prednisone courses to achieve remission. Based on the relapse rate, the patients were classified as frequently relapsing or steroid-dependent; that is patients in most urgent, effective, and safer treatment $(7,10)$. The current study aimed at evaluating the epidemiological factors and their correlation with nephritic syndrome outcomes including steroiddependent, frequently relapsing, and steroid resistance.

\section{Methods}

\subsection{Study Setting}

It was as a case series study conducted in pediatric clinic of Amirkabir hospital.

\subsection{Ethical Considerations}

Authors completely observed ethical issues (double publication, including plagiarism, and data fabrication. (In addition, the ethical committee of Arak University of Medical Sciences approved the study protocol. 


\subsection{Study Population}

The patients were selected by representative sampling from children $<15$ years old with nephritic syndrome diagnosis. The study data were obtained from patientphysician interviews. The current study considered 100 children with NS diagnosis. To determine the drug responses, each child was given prednisolone $(2 \mathrm{mg} / \mathrm{kg} /$ day with maximum dose of $60 \mathrm{mg}$ /day) for four weeks; based on their responses to corticosteroids in one month, children were divided into four groups as steroid responded, steroid resistant, frequent relapse, and steroid dependent.

\subsection{Statistical Analysis}

Data analysis was conducted by chi-square test with SPSS at a significant level of $<0.05$.

\subsection{Measurements}

Epidemiological and clinical information were obtained by physician-patient interviews on admission to hospital.

\subsection{Inclusion and Exclusion Criteria}

Age less than 15 years, consent to participate in the research project, and absence of another congenital kidney disease were considered as inclusion criteria; in addition, presence of severe liver, kidney, or cardiac diseases, and dissatisfied with personal data utilization in the current study were considered as exclusion criteria.

\section{Results}

Epidemiological and clinical information of children with NS are shown in Table 1 . In some of the variables such as gender $(P=0.004)$, gestational age $(P=0.001)$, diabetic nephropathy $(\mathrm{P}=0.007)$, prerenal azotemia $(\mathrm{P}=0.001)$, allergies $(\mathrm{P}=0.001)$, microscopic hematuria $(\mathrm{P}=0.001)$, delivery type $(P=0.001)$, passive smoking $(P=0.001)$, child's body mass index $(\mathrm{BMI})(\mathrm{P}=0.001)$, and neonatal jaundice $(\mathrm{P}$ $=0.001)$ a statistically significant difference was observed among the groups $(\mathrm{P}=0.007)$.

Also, about epidemiological and clinical information of children families, indicated in Table 2, a statistically significant difference was observed among the groups in some factors including economic status $(\mathrm{P}=0.001)$, mother's BMI $(\mathrm{P}=0.011)$, mother's pregnancy age $(\mathrm{P}=$ $0.04)$, preeclampsia $(\mathrm{P}=0.04)$, gestational hypertension ( $\mathrm{P}$ $=0.001)$, consanguineous marriage $(\mathrm{P}=0.001)$, and passive smoking of mothers $(\mathrm{P}=0.001)$. The results showed a better status of the steroid responded group compared with the other groups.

\section{Discussion}

The current study investigated the epidemiological and clinical information of children in different types of NS outcomes.

In a study by Chanchlani et al., on ethnic differences in NS, they reported that drug responses in NS outcomes varied with ethnicity (11). In another study by Huttunen et al., on Finnish type of congenital NS, they observed slight increases in blood urea nitrogen in 14 cases and $50 \%$ death of the children before six months without frank uremia developed before death (12). A study on the epidemiology of renal failure (RF) expressed high incidence of RF at PUHC-CDG of Ouagadougou (13). Takahashi et al., conducted a study on relapse triggers in children with steroid dependency; they observed 442 relapses in 2499 patients (14). Yousefichaijan et al., observed no statistically significant correlation between children with attention deficit hyperactivity disorder (ADHD) and steroiddependent nephrotic syndrome (SDNS), and their healthy counterparts (15), which was not investigated in the current study. Sreenivasa et al., concluded that urinary tract infections (UTIs) are a common infection, which can lead to NS (16). In Feehally et al., concluded that NS was more preponderant in children living in the Leicester city (17). Mangia et al., observed that RF was associated with a wide range of different etiologies and different levels of morbidity, and consequently influenced the outcome of disease (18). Ruggenenti et al., concluded that Rituximab reduces immunosuppression needs in steroid-dependent or frequently relapsing nephrotic syndrome (19). The current study limitation was defective epidemiologic questionnaire completion by parents; after explaining to parents about the effect of NS on kidney and other body systems they agreed to cooperate. Furthermore, it is recommended to confirm the results by further studies.

\subsection{Conclusion}

Steroid resistant, frequent relapsing, and steroid dependent outcomes of NS in children increased with particular distribution related to epidemiologic factors including gender, gestational age, diabetic nephropathy, prerenal azotemia, allergies, etc. Based on this epidemiological status, modification can influence and increase NS outcomes.

\section{Acknowledgments}

The authors gratefully acknowledge their gratitude to the research council of Arak University of Medical Sciences (Grant Number: 2700) for the financial support. 


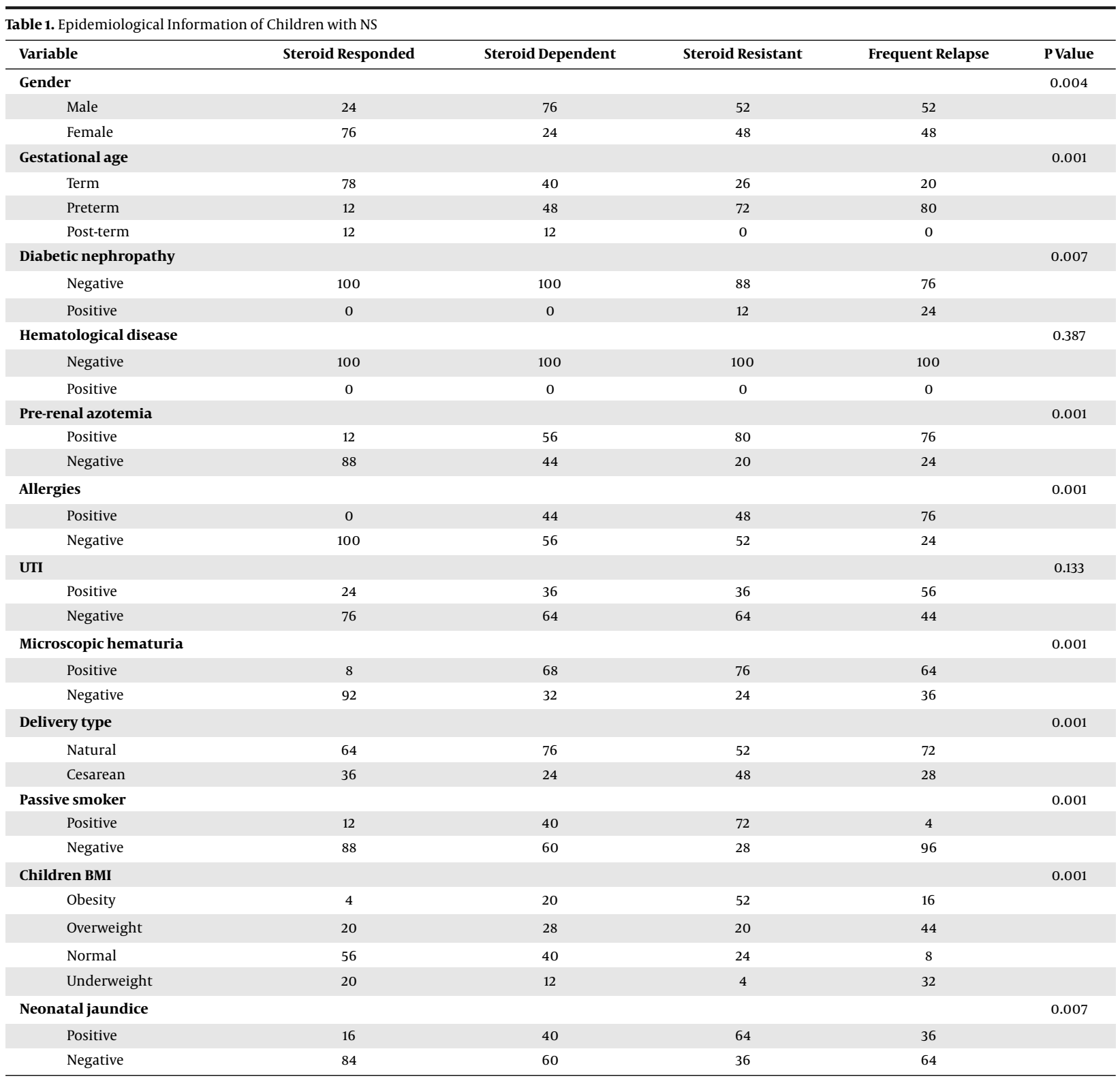

\section{Footnote}

Conflicts of Interest: The authors declared no conflict of interests.

\section{References}

1. Yousefichaijan P, Rezagholizamenjany M, Dorreh F, Shariatmadari F, Ghandi Y, Alinejad S. Serum Vitamin D Status in reflux nephropathy. Sch J App Med. 2016;4(12):4325-7.

2. Teeninga N, Kist-van Holthe JE, van den Akker EL, Kersten MC, Boersma E, Krabbe HG, et al. Genetic and in vivo determinants of glucocorticoid sensitivity in relation to clinical outcome of childhood nephrotic syndrome. Kidney Int. 2014;85(6):1444-53. doi: 10.1038/ki.2013.531. [PubMed: 24429396].
3. Buscher AK, Beck BB, Melk A, Hoefele J, Kranz B, Bamborschke D, et al. Rapid Response to Cyclosporin A and Favorable Renal Outcome in Nongenetic Versus Genetic Steroid-Resistant Nephrotic Syndrome. Clin J Am Soc Nephrol. 2016;11(2):245-53. doi: 10.2215/CJN.07370715. [PubMed: 26668027]. [PubMed Central: PMC4741047].

4. Rezagholi-Zamnjany M, Yousefichaijan P. An overview on peritoneal dialysis. Ann Res Dial. 2016;1(1).

5. Guitard J, Hebral AL, Fakhouri F, Joly D, Daugas E, Rivalan J, et al. Rituximab for minimal-change nephrotic syndrome in adulthood: predictive factors for response, long-term outcomes and tolerance. Nephrol Dial Transplant. 2014;29(11):2084-91. doi: 10.1093/ndt/gfu209. [PubMed: 24920841].

6. Bazzi C, Rizza V, Casellato D, Tofik R, Berg AL, Gallieni M, et al. Fractional excretion of IgG in idiopathic membranous nephropathy with nephrotic syndrome: a predictive marker of risk and drug 
responsiveness. BMC Nephrol. 2014;15:74. doi: 10.1186/1471-2369-15-74. [PubMed: 24886340]. [PubMed Central: PMC4018618].

7. Inaba $\mathrm{A}$, Hamasaki $\mathrm{Y}$, Ishikura $\mathrm{K}$, Hamada $\mathrm{R}$, Sakai $\mathrm{T}$, Hataya $\mathrm{H}$, et al. Long-term outcome of idiopathic steroid-resistant nephrotic syndrome in children. Pediatr Nephrol. 2016;31(3):425-34. doi: 10.1007/s00467-015-3174-7. [PubMed: 26335197].

8. Lombel RM, Gipson DS, Hodson EM, Kidney Disease: Improving Global O. Treatment of steroid-sensitive nephrotic syndrome: new guidelines from KDIGO. Pediatr Nephrol. 2013;28(3):415-26. doi: 10.1007/s00467-012-2310-x. [PubMed: 23052651].

9. Yousefichaijan P, Rezagholizamenjany M, Dorreh F, Rafiei M, Taherahmadi H, Niyakan Z, et al. Comparison of development indicators, according to ages and stages questionnaires in children with pollakiuria compared to healthy children. Nephrourol Mon. 2017;9(4). doi: 10.5812/numonthly.45898.

10. Kamei K, Ogura M, Sato M, Sako M, Iijima K, Ito S. Risk factors for relapse and long-term outcome in steroid-dependent nephrotic syndrome treated with rituximab. Pediatr Nephrol. 2016;31(1):89-95. doi: 10.1007/s00467-015-3197-0. [PubMed: 26341251].

11. Chanchlani R, Parekh RS. Ethnic Differences in Childhood Nephrotic Syndrome. Front Pediatr. 2016;4:39. doi: 10.3389/fped.2016.00039. [PubMed: 27148508]. [PubMed Central: PMC4835686].

12. Huttunen NP. Congenital nephrotic syndrome of Finnish type. Study of 75 patients. Arch Dis Child.1976;51(5):344-8. doi: 10.1136/adc.51.5.344. [PubMed: 938078]. [PubMed Central: PMC1545982].

13. Gérard C, Hamidou S, Evariste BB, Roger KA, Fla K, Manan HK, et al.
Epidemiology of renal failure in children at the pediatric university hospital charles De-Gaulle of Ouagadougou (Burkina Faso). Open J Pediatr. 2016;6(1):141-8. doi: 10.4236/ojped.2016.61021.

14. Takahashi S, Wada N, Murakami H, Funaki S, Inagaki T, Harada K, et al. Triggers of relapse in steroid-dependent and frequently relapsing nephrotic syndrome. Pediatr Nephrol. 2007;22(2):232-6. doi: 10.1007/s00467-006-0316-y. [PubMed: 17043884].

15. Yousefichaijan P, Salehi B, Rafiei M, Dahmardnezhad M, Naziri M. The correlation between attention deficit hyperactivity disorder and steroid-dependent nephrotic syndrome. Saudi J Kidney Dis Transpl. 2015;26(6):1205-9. doi: 10.4103/1319-2442.168624. [PubMed: 26586060].

16. Sreenivasa B, Murthy CS, Raghavendra K, Basavanthappa S, Pejaver R, Jadala HV. Urinary tract infection at presentation of nephrotic syndrome: A clinical evaluation. Indian J Child Health. 2015;2(1):1-4.

17. Feehally J, Kendell NP, Swift PG, Walls J. High incidence of minimal change nephrotic syndrome in Asians. Arch Dis Child.1985;60(11):101820. doi: 10.1136/adc.60.11.1018. [PubMed: 4073934]. [PubMed Central: PMC1777627].

18. Mangia C, Andrade M. Epidemiological aspects of kidney failure in hospitalized children in Brazil. J Nephrol Ther. 2015;6(245):2161-70.

19. Ruggenenti P, Ruggiero B, Cravedi P, Vivarelli M, Massella L, Marasa $\mathrm{M}$, et al. Rituximab in steroid-dependent or frequently relapsing idiopathic nephrotic syndrome. J Am Soc Nephrol. 2014;25(4):850-63. doi: 10.1681/ASN.2013030251. [PubMed: 24480824]. [PubMed Central: PMC3968490]. 
Table 2. Familial Epidemiological Information of Children with NS

\begin{tabular}{|c|c|c|c|c|c|}
\hline Variable & Steroid Responded & Steroid Dependent & Steroid Resistant & Frequent Relapse & P Value \\
\hline Father's occupation & & & & & 0.062 \\
\hline Unemployed & 4 & 0 & 8 & 16 & \\
\hline Worker & 16 & 28 & 36 & 24 & \\
\hline Employee & 76 & 64 & 52 & 36 & \\
\hline Mother's occupation & & & & & 0.064 \\
\hline Unemployed & 20 & 28 & 16 & 12 & \\
\hline Self-employed & 0 & 0 & 8 & 32 & \\
\hline Worker & 16 & 12 & 32 & 12 & \\
\hline Employee & 64 & 60 & 44 & 44 & \\
\hline Father's education & & & & & 0.470 \\
\hline Under diploma & 0 & 16 & 28 & 16 & \\
\hline Diploma & 8 & 24 & 20 & 20 & \\
\hline Associate & 20 & 8 & 4 & 8 & \\
\hline Bachelor & 52 & 40 & 32 & 40 & \\
\hline Master's degree and higher & 20 & 12 & 16 & 16 & \\
\hline Mother's education & & & & & 0.194 \\
\hline Diploma & 28 & 32 & 28 & 28 & \\
\hline Associate & 8 & 8 & 4 & 0 & \\
\hline Bachelor & 44 & 36 & 32 & 36 & \\
\hline Master's degree and higher & 20 & 16 & 4 & 24 & \\
\hline Economic status, USS & & & & & 0.001 \\
\hline$<250$ & 12 & 0 & 4 & 8 & \\
\hline $250-500$ & 0 & 24 & 28 & 12 & \\
\hline$>500$ & 88 & 76 & 68 & 80 & \\
\hline Maternal BMI, kg/m² & & & & & 0.011 \\
\hline Obesity & 4 & 44 & 48 & 40 & \\
\hline Normal & 68 & 44 & 20 & 32 & \\
\hline Underweight & 12 & 4 & 12 & 12 & \\
\hline Maternal pregnancy age, y & & & & & 0.004 \\
\hline $18>$ & 0 & 0 & 4 & 4 & \\
\hline $18-24$ & 44 & 4 & 4 & 12 & \\
\hline $25-29$ & 48 & 28 & 12 & 0 & \\
\hline $30-34$ & 8 & 52 & 44 & 32 & \\
\hline $35<$ & 0 & 16 & 36 & 52 & \\
\hline Preeclampsia & & & & & 0.004 \\
\hline Positive & 4 & 4 & 52 & 52 & \\
\hline Negative & 96 & 56 & 48 & 48 & \\
\hline Eclampsia & & & & & 0.432 \\
\hline Positive & 12 & 0 & 4 & 4 & \\
\hline Negative & 88 & 100 & 96 & 96 & \\
\hline Diabetes & & & & & 0.118 \\
\hline Pre-gestational & 8 & 24 & 40 & 20 & \\
\hline Gestational & 24 & 24 & 36 & 32 & \\
\hline No diabetes & 68 & 52 & 24 & 48 & \\
\hline Gestational HTN & & & & & 0.001 \\
\hline Positive & 8 & 32 & 76 & 68 & \\
\hline Negative & 92 & 68 & 24 & 32 & \\
\hline Chronic HTN & & & & & 0.058 \\
\hline Positive & 20 & 52 & 56 & 52 & \\
\hline Negative & 80 & 48 & 44 & 48 & \\
\hline
\end{tabular}


Consanguineousmarriage

\begin{tabular}{|c|c|c|c|c|c|}
\hline Positive & 12 & 40 & 76 & 72 & \\
\hline Negative & 88 & 60 & 24 & 28 & \\
\hline Living place & & & & & 0.572 \\
\hline City & 76 & 52 & 68 & 60 & \\
\hline Village & 24 & 48 & 32 & 40 & \\
\hline Mother's passive smoking & & & & & 0.001 \\
\hline Positive & 20 & 52 & 80 & 72 & \\
\hline Negative & 80 & 48 & 20 & 28 & \\
\hline
\end{tabular}

